\title{
CORONAVIRUS
}

\section{Hydrogen peroxide mouthwash}

A commentary on this letter has been published.

Sir, there is a commercially available mouthwash containing $1.5 \%$ effective hydrogen peroxide on the market (Peroxyl, Colgate-Palmolive Ltd) which is above the recommended $0.5 \%$ concentration required to be virucidal to coronavirus. ${ }^{1}$ It may therefore be worth recommending the routine use of such a mouthwash pre-operatively when dental treatment is to be delivered as urgent care, so any subsequent droplet contamination from the oropharyngeal complex can be rendered potentially less infective.

Following a specific study on droplet contamination on surfaces by COVID-19 with various dental procedures, it may also substantially modify or reduce the decontamination time between patients and render the working environment for our professionals safer.

\section{R. Saravanamuttu, London, UK}

\section{Reference}

1. Romesh A, Thomas J T, Muraliharan N P, Vargese S S Efficacy of adjunctive use of hydrogen peroxide with chlorhexidine as a procedural mouthwash on dental aerosol. Nat J Physiology, Pharmacy Pharmacology 2015; 5: 431-435.

\section{https://doi.org/10.1038/s41415-020-1643-2}

\section{High aerosol generating potential}

Sir, the current pandemic situation has forced us to re-evaluate and adapt perhaps most parts of our practice which we (unfortunately?) took for granted it seems. Inhalation sedation (IS), possessing a high aerosol generating potential is certainly not immune to the debate. The unique challenge in this case is that IS has been constantly addled by numerous regulations on top of varied guidelines (IACSD, EAPD, ANZCA,
AAP) depending upon which region of the world one happens to be practising in. These guidelines vary over a wide spectrum of specifications such as written confirmation of informed consent (IACSD, EAPD only), pulse oximeter and documented clinical monitoring (ANZCA), training in paediatric advanced life support and IV access (AAP), formal IS training for practitioners and $\mathrm{CPR}$ training (ANZCA, IACSD). ${ }^{1}$ There are even differences in equipment installation and maintenance recommendations. ${ }^{1}$

A testament to the possible variation of regulations which would in turn affect the way IS is practised is the fact that across Europe, 51 countries possess individual regulations for IS practice and 53 separate state dental boards in the USA regulate IS practice in their areas of jurisdiction. These guidelines are then subject to the recommendations of various local regulatory bodies.

It is surprising to note that quite a few regions of the world do not follow a given set of guidelines. This glaring oversight becomes more pronounced in today's situation where practitioners are preferring extractions over routine endodontics and for cases where children might have to undergo extraction of painful/abscessed teeth. Clarity on the safety of IS would help resolve a number of dilemmas today and in the future.

It might be argued that oral sedation is used if doubts exist. While that might be valid to an extent, the predictability of IS should outweigh this as COVID-19 is not the only medical risk of which one should be wary. Surely there is a limit as to how much out of our way we can go to avoid the virus? IS should be preferred over inhalational sedation in situations wherein a choice must be made; it certainly trumps oral sedation as far as predictability and dose adjustment are concerned.

Then again, not all guidelines insist upon formal IV access training. So we can see how this is a problem. The guidelines are as varied as the challenges presented and there are more chances of encountering lacunae in practice. It seems that unifying IS practice protocols is needed now more than ever to bring clarity. This includes the roles of each team member, following routine decontamination procedures, operatory ventilation and attendance guidelines, and above all in relation to aerosol generation, use it only when absolutely necessary and when no other viable alternative presents itself. Vaibhav Sahni, New Delhi, India

\section{Reference}

1. Rajan S, Manton D J, Bhujel N. A review of contemporary inhalation sedation guidelines and regulations related to treating children. Faculty Dent J 2017; 8: 112-118.

https://doi.org/10.1038/s41415-020-1700-x

\section{Substance 'disuse' during crisis}

Sir, the fatality rate of COVID-19 with no pre-existing comorbidity is on average $0.9 \%$ while tobacco kills millions of healthy individuals worldwide. ${ }^{1}$ The failure of substance abusers to quit is explained by their addictive and euphoric action. Strict lockdown measures and supply of only essential services have dampened the sale of tobacco and its products. Socialising promotes substance abuse, whereas self-isolation and family bonding time may provide support linked to smokers attempting to quit, achieve abstinence and overcome withdrawal. ${ }^{2}$ Internet-based cognitive behaviour may minimise loneliness and the inclination towards substance abuse. ${ }^{3}$ 
An additional consideration is that smokeless tobacco users constantly spit their saliva that can harbour viral strains 29 days' post infection. ${ }^{4}$

Perhaps there is a silver lining with nature providing the possibility of substance 'disuse' during actions to stem this unprecedented crisis.

S. S. Shetty, Manipal, India; R. Jayaraj, Adelaide, Australia; Y. Merchant, Bangalore, India; N. Shabadi, Virajpet, India

\section{References}

1. Wilson N, Kvalsvig A, Barnard L T, Baker M G. Casefatality risk estimates for COVID-19 calculated by using a lag time for fatality. Emerg Infectious Dis 2020; 26.

2. Hubbard G, Gorely T, Ozakinci G, Polson R, Forbat L. A systematic review and narrative summary of familybased smoking cessation interventions to help adults quit smoking. BMC Fam Pract 2016; 17: 73.

3. Käll A, Jägholm S, Hesser $\mathrm{H}$ et al. Internet-based cognitive behavior therapy for loneliness: a pilot randomized controlled trial. Behav Ther 2020; 51 54-68.

4. Barzon L, Pacenti M, Berto A et al. Isolation of infectious Zika virus from saliva and prolonged viral RNA shedding in a traveller returning from the Dominican Republic to Italy, January 2016. Eurosurveillance 2016; 21: 30159.

https://doi.org/10.1038/s41415-020-1699-z

\section{A plausible transmission mode}

Sir, the established modes of SARS-CoV-2 transmission may be an incomplete picture. In their most recent scientific brief, the World Health Organisation acknowledge the evidence to support contact and respiratory droplet transmission of SARS-CoV-2. Accordingly, much of the government's infection prevention and control guidance for COVID-19 is centred around minimising transmission via these methods. The coronaviruses implicated in the previous SARS and MERS outbreaks caused enteric manifestations in conjunction with the respiratory symptoms experienced by many with COVID-19. Since the early retrospective cohort studies of patients in Wuhan, more recent observational studies report common gastrointestinal symptoms to be more prevalent than previously thought. ${ }^{1}$

SARS-CoV and MERS-CoV RNA were frequently detected in stool specimens of infected individuals. The New England Journal of Medicine case report of the first COVID-19 patient in the USA detected high SARS-CoV-2 viral load in their stool sample. ${ }^{2}$ Experts recognise the hypothesised faecal-oral route to be a plausible mode of transmission.
This route can facilitate transmission via fomites in the surrounding environment, in much the same way as indirect respiratory droplet transmission. Where toothbrushes are placed in close proximity to a toilet, there may be a heightened risk of harbouring SARS-CoV-2 from infected individuals. That families often house toothbrushes together, the risk of infecting other individuals could be made easier.

Rightly, the dental profession have reason to fear the aerosol generation from dental handpieces, particularly when the inversesquare law is applied to project the extent of dispersal. In a mechanistically similar way, toilet plumes may pose a similar challenge. Professor Addy offered reason to reinforce the role of toothbrushing with toothpaste, given the antimicrobial properties of toothpaste ingredients. ${ }^{3}$ Awareness and advice to limit toothbrush contamination might prove beneficial. Though the evidence base is yet to be established, no harm exists in recommending this as a precautionary measure in the preventive approach to COVID-19.

\section{J. Patel, Leeds, UK}

\section{References}

1. Cholankeril G, Podboy A, Aivaliotis V et al. High prevalence of concurrent gastrointestinal manifestations in patients with SARS-CoV-2: Early experience from California. Gastroenterology 4 April 2020; doi. org/10.1053/j.gastro.2020.04.008. (Epub ahead of print)

2. Holshue M, DeBolt C, Lindquist S et al. First Case of 2019 Novel Coronavirus in the United States. N Engl J Med 2020; 382: 929-936.

3. Addy M. Toothbrushing against coronavirus. Br Dent J 2020; 228: 487.

https://doi.org/10.1038/s41415-020-1698-0

\section{Progression of specialist trainees}

Sir, amid the many current uncertainties dental practitioners have, trainees also have an additional worry regarding their training and how this will impact them in the future. The bearing COVID-19 has had on clinical activity means that many patients being treated and prepared for cases will be delayed, target case numbers and important clinical exposure will reduce, negatively impacting trainees' progression. Additionally, redeployment into other areas of the trust to aid with the response to COVID-19 may divert trainees' attention from their own speciality. With royal colleges already cancelling and postponing courses and exams, this adds the stress on trainees approaching the end of the pathway across all specialities.

All resources should and will be directed into ensuring facilities and measures to protect the safety and wellbeing of patients. However, a structure needs to be developed to account for the disruption in training COVID-19 has caused and facilitate the progression of the trainees without compromising the quality and integrity of the respected specialities.

M. Shaath, Manchester, UK https://doi.org/10.1038/s41415-020-1697-1

\section{COVID PDPs}

Sir, the COVID-19 pandemic has caused significant disruptions in dental services including both undergraduate and postgraduate dental training. Newly qualified dentists who commenced dental foundation training in September 2019 would have only had seven months of clinical practice before the lockdown resulted in cessation of routine dentistry in the UK. ${ }^{1}$ There are likely to be outstanding competencies and the loss of clinical experience and mentoring will need to be identified and fulfilled through a personal development plan (PDP).

The enhanced continuing professional development (CPD) scheme was introduced by the General Dental Council (GDC) on 1 January 2018 for dentists. ${ }^{2}$ This involves completion of the prerequisite 100 hours of CPD per cycle but also in ensuring that this is tailored to meet individual PDPs to make sure maximum benefit is gained and to encourage reflective practice.

At present, PDPs are not a routine part of the undergraduate curricula ${ }^{3}$ and as such, newly qualified dentists will be faced with the new challenge of having to proactively plan their CPD to fulfil outstanding competencies from their current training course. This is also likely to be the case for dentists in dental core training, speciality training and those undertaking formal postgraduate qualifications.

GDC standards allow PDPs to be completed individually or in conjunction with peers including employers. ${ }^{2}$ Dentists in training should seek advice from their educational supervisors and postgraduate deaneries by identifying areas within their professional activities where further training is needed, identify suitable courses 